\title{
1 The August 2011 URSI World Day Campaign: Initial Results
}

2 Thomas J. Immel ${ }^{\mathrm{a},{ }^{*}}$, Guiping Liu ${ }^{\mathrm{a}}$, Scott L. England ${ }^{\mathrm{a}}$, Larisa P. Goncharenko ${ }^{\mathrm{b}}$, Philip J. Erickson ${ }^{\mathrm{b}}$,

3 Mykhaylo V. Lyashenko ${ }^{\mathrm{c}}$, Marco Milla ${ }^{\mathrm{d}}$, Jorge Chau ${ }^{\mathrm{e}}$, Harald U. Frey ${ }^{\mathrm{a}}$, Stephen B. Mende ${ }^{\mathrm{a}}$, Qihou

4 Zhou $^{\mathrm{f}}$, Anja Stromme ${ }^{\mathrm{g}}$, Larry J. Paxton ${ }^{\mathrm{h}}$

$5 \quad{ }^{a}$ Space Sciences Laboratory, University of California, Berkeley, CA, 94720, USA

$6 \quad{ }^{\mathrm{b}}$ MIT Haystack Observatory, Westford, Massachusetts, USA

$7 \quad{ }^{\mathrm{c}}$ Institute of Ionosphere, National Academy of Sciences of Ukraine, Ministry of Education and

8 Science of Ukraine, Kharkov, Ukraine

$9 \quad{ }^{\mathrm{d}}$ Jicamarca Radio Observatory, Instituto Geofisico del Peru, Lima, Peru

$10{ }^{\mathrm{e}}$ Leibniz Institute of Atmospheric Physics at the Rostock University, Germany

$11{ }^{\mathrm{f}}$ Electrical and Computer Engineering Department, Miami University, Oxford, OH, USA

$12{ }^{\mathrm{g}}$ Center for Geospace Studies SRI International, 333 Ravenswood Avenue, Menlo Park, USA

$13{ }^{\mathrm{h}}$ Applied Physics Laboratory, Johns Hopkins University, Laurel, MD, USA

$14{ }^{*}$ Corresponding author. Tel.: +15106433504; E-mail address: $\underline{\text { immel@ @sl.berkeley.edu }}$

\section{Abstract}

17 During a 10-day URSI World Day observational campaign beginning on August 1, 2011, an

18 isolated, major geomagnetic storm occurred. On August 5, Kp reached values of $8^{-}$and $D s t$ dropped

19 to -113 nT. The occurrence of this isolated storm in the middle of a 10-day URSI World Day

20 campaign provides and unprecedented opportunity to observe the coupling of solar wind energy into

21 the magnetosphere and to evaluate the varied effects that occur in the coupled magnetosphere-

22 ionosphere-thermosphere system. Dramatic changes in the ionosphere are seen at every one of the

23 active radar stations, extending from Greenland down to equatorial Peru in the American sector and 
1 at middle latitudes in Ukraine. Data from TIMED and THEMIS are shown to support initial

2 interpretations of the observations, where we focus on processes in the middle latitude afternoon

3 sector during main phase, and the formation of a dense equatorial ionosphere during storm recovery.

4 The combined measurements strongly suggest that the changes in ionospheric conditions observed

5 after the main storm phase can be attributed in large part to changes in the stormtime thermosphere.

6 This is through the generation of disturbance dynamo winds and also global neutral composition

7 changes that either reduce or enhance plasma densities in a manner that depends mainly upon

8 latitude. Unlike larger storms with possibly more sustained forcing, this storm exhibits minimal

9 effects of persistent meridional stormtime wind drag, and little penetration of solar wind electric

10 potentials to low latitudes. It is, therefore, an outstanding example of an impulsive event that

11 exhibits longer-term effects through modification of the background atmosphere. 
2 1. Introduction

3 The incoherent scatter radars (ISRs) at Sondrestrom ( $\mathrm{SON}: 67^{\circ} \mathrm{N}, 51^{\circ} \mathrm{W} ; 73^{\circ} \mathrm{N}$ geomagnetic latitude),

4 Millstone Hill (MLH:42.6º $\mathrm{N}, 71.5^{\circ} \mathrm{W} ; 53^{\circ} \mathrm{N}$ geomagnetic latitude), Arecibo (ARO: $18.3^{\circ} \mathrm{N}, 66.7^{\circ} \mathrm{W}$;

$532^{\circ} \mathrm{N}$ geomagnetic latitude), and Jicamarca (JRO: $11.95^{\circ} \mathrm{S}, 76.87^{\circ} \mathrm{W} ; 0.6^{\circ} \mathrm{N}$ geomagnetic latitude),

6 and Kharkov (KHA: $49.6^{\circ} \mathrm{N}, 36.3^{\circ} \mathrm{E} ; 45.7^{\circ} \mathrm{N}$ geomagnetic latitude) operated continuously during

7 August 1-10, 2011 as part of the URSI World Day campaign (http://www.eiscat.se). Three of these

8 radars are located at different latitudes close to the $70^{\circ} \mathrm{W}$ meridian (see Figure 1). Sondrestrom is at

9 high latitude in the auroral zone/polar cap boundary. Millstone Hill is at middle latitude, but it could

10 be considered in the subauroral zone especially during geomagnetic storm conditions (e.g.

11 Buonsanto et al., 1999a, 1999b). Arecibo is at low latitude, and it lies well north the equatorial

12 anomaly. Jicamarca is at the magnetic equator, though south of the geographic equator. Kharkov is

13 located at about $100^{\circ}$ east of this chain of radars, $\sim 7$ hours later in local time. Thus, this campaign

14 provided a extensive, coordinated set of observations of the ionosphere, extending from the auroral

15 zone to the equator during the geomagnetic storm that occurred during the 10-day period.

16 Drs. England and Liu requested the August 2011 World Day campaign for investigations of

17 atmospheric planetary wave activities and interaction with the ionosphere. For the intended science

18 goal, the participation of MLH, JRO, and ARO ISRs was specifically requested, and was

19 successfully provided. SON and KHA ISRs offered their participation and joined the observation

20 campaign voluntarily. The study period coincides with the onset of a major geomagnetic storm

21 occurring on August 5. Starting at 0619 UT on August 2, the first of three M-class solar flares

22 erupted from the sunspot region 1263. The third and largest of the flares (M9-class) peaked in X-ray 
1 flux at 0357 UT on August 4, launching an associated coronal mass ejection that arrived around

21900 UT on August 5. The solar wind conditions are captured upstream by NASA's ACE satellite,

3 showing the arrival of a remarkable disturbance with high density (up to $40 \mathrm{H}^{+} / \mathrm{cc}$ ) and magnetic

4 field strength (>25 nT for 6 hours). Furthermore, Bz was southward (in GSM coordinates) for

5 approximately half the time during the passage of the CME, reaching at one point $-20 \mathrm{nT}$. This

6 combination of parameters indicates a strong coupling of the solar wind and magnetosphere, with

7 the expected resultant increase in activity in geospace. See Newell et al. (2008) for a detailed review

8 of energy coupling functions.

9 The World Day ISRs provides the capability to study the changes of the ionosphere that occur in

10 response to this energy input (e.g. Buonsanto 1999; Buonsanto et al., 1999a, 1999b; Goncharenko et

11 al., 2005). Observations of ionospheric parameters, including electron density $\left(N_{e}\right)$, electron

12 temperature $\left(T_{e}\right)$, ion temperature $\left(T_{i}\right)$, and ion drift velocity $\left(V_{o}\right)$, are provided, supporting a

13 characterization of the ionospheric response to the storm. Dramatic variations during this storm

14 times are observed in the ionosphere on a large-scale.

15 These ISR observations are supplemented by space-based observations. The GUVI instrument on

16 TIMED (Christensen et al., 2003) captures the variable condition of thermospheric composition that

17 strongly influences ionospheric production and loss. The NASA THEMIS spacecraft, as well as the

18 ground-based observations of the North American THEMIS GBO network, observe conditions in

19 the inner magnetosphere and auroral ionosphere. This comprehensive set of observations provides

20 insight into the coupling of solar wind energy into the ionosphere and the subsequent response. The

21 goal of this report is to provide a full initial description of the collected observations, highlighting

22 some of the outstanding system behaviors evident in the course of this storm. 
2 2.1. Observations of the geomagnetic conditions and their drivers.

3 The geomagnetic indices of $K p$ and $D s t$ are displayed in Figure 2 for August 1-11, 2011 during the

4 URSI World Day campaign. The $K p$ values are very low at only 0-2 during the early period of the

5 campaign from August 1-4. On August 5, the value increases at the interval of 1500-1800 UT and

6 reaches the largest value of $8^{-}$at 2100-2400 UT, following the arrival of the CME at the

7 magnetopause. The following day, $K p$ decreases and gradually reaches lower values in the range of

$8 \quad 1-2$ at the end of the day. The change in Dst features a sharp increase (onset) followed by a rapid

9 decrease during 1800-2400 UT on August 5 (main phase). Main phase continues for several hours

10 on August 6 and $D s t$ reaches the lowest value of $-113 \mathrm{nT}$ at $0300 \mathrm{UT}$ on August 6. After that, Dst

11 starts to recover and gradually approaches $0 \mathrm{nT}$ by the end of the campaign on August 11 . This time

12 series of Dst indicates the occurrence of a major geomagnetic storm.

13 The z-component (GSM) of the solar wind magnetic field component and the solar wind dynamic

14 pressure are shown in Figure 3. Observed near the Earth-Sun L1 point by the Advanced

15 Composition Explorer (ACE) satellite, these data are time-shifted to represent arrival time of the

16 conditions at Earth. This is done in a simple manner, where Bz and pressure are delayed according

17 to the 5-minute mean of the observed solar wind velocity throughout the storm period. These two

18 parameters effectively predict important solar wind inputs at the boundary of Earth's magnetosphere

19 that lead to the geomagnetic event.

20 A sharp increase in solar wind pressure just after 1800 UT marks the start of the event, with peaks in

21 pressure occurring over the next 2 hours and a final spike above $20 \mathrm{nPa}$ (and, not shown, 40

22 protons/cc) ending at $21 \mathrm{UT}$. Thereafter the pressure varies around 3-5 $\mathrm{nPa}$, well above the pre-CME 
1 level of approximately $1 \mathrm{nPa}$. In the IMF measurements, the features to note are the doubling of $|\mathbf{B}|$

2 to $10 \mathrm{nT}$ after $1800 \mathrm{UT}$ (coincident with the first density increase), and another major increase to

$3 \sim 30 \mathrm{nT}$ at $1900 \mathrm{UT} . \mathrm{B}_{\mathrm{z}}$ is quite variable until $\sim 2100 \mathrm{UT}$, at which time it turns to $-20 \mathrm{nT}$ for almost

42 hours. The rest of the period is marked by significant polarity reversals of $B_{z}$, with frequent

5 periods of southward $\mathrm{B}_{\mathrm{z}}$ through to $1600 \mathrm{UT}$ on August 6 , as $|\mathbf{B}|$ drops below $10 \mathrm{nT}$ again.

7 Magnetic field observations by the Time History of Events and Macroscale Interactions During

8 Substorms (THEMIS; Angelopoulos et al., 2008) are shown in Figure 4. The THEMIS-A spacecraft

9 data are shown, whose 12-Re apogee elliptical orbit of 12 Re extends into the dusk sector (+y GSE

10 sense) during this time period. The THEMIS satellite is in an outstanding position to support this

11 storm study, for its 24-hour orbit period and apogee place it in the afternoon sector along with the

12 radars at onset. Figure 1 shows the THEMIS orbit footpoint along with the ISR locations, mapped

13 with the T89 magnetospheric magnetic field model set to quiet times to illustrate the general

14 mapping (Tsyganenko, 1989). At 1902 UT on August 5, all three components of the THEMIS

15 magnetic field measurement show sharp departures from their normal trends, and $B z$ then suddenly

16 drops southward before 20 UT, followed by rapid fluctuations with both positive (northward) and

17 negative (southward) values. The outstanding observations serve as an accurate time marker for the

18 commencement of storm effects that are matched by the sudden increase in hourly Dst, an

19 occurrence that is also indicative of a sudden compression of the magnetopause. 
1 The response of the terrestrial plasma environment to the storm input is extensive. Global maps of

2 assimilated vertical total electron content (TEC) measurements, derived from ground-based

3 receivers of global navigation satellite system (GNNS) radio signals, provide a summary of the

4 changes [Rideout and Coster, 2006]. Two 20-minute intervals of global measurements are shown

5 from 0600-0620 UT on August 5 and 6 in the two panels of Figure 5. The first panel shows TEC in

6 pre-storm undisturbed conditions and the second shows the same approximately 10 hours after

7 storm onset. The differences are noticeable almost everywhere, with major reductions (-30 to -60\%)

8 of plasma density over the Americas, and similarly large enhancements over South Asia and Africa.

9 Note that this snapshot in time captures nighttime conditions over the Americas, and daytime

10 conditions over Asia. At all of the ISR sites shown in this work, a storm-time reduction in TEC is

11 evident at 6 UT on August 6. This is corroborated by each of the data sets shown here.

12 The ISR measurements for August 1-11 of 2011 during the URSI World Day campaign provide

13 observations of ionospheric parameters, including electron density $\left(N_{e}\right)$, electron temperature $\left(T_{e}\right)$,

14 ion temperature $\left(T_{i}\right)$, and ion drift velocity $\left(V_{o}\right)$. Observations at Sondrestrom, Millstone Hill,

15 Arecibo, Jicamarca, and Kharkov are presented and discussed. A "quicklook" summary of the

16 variations observed at all of the stations is provided in Table 1. Though grossly simplified, it

17 provides a picture of the changes observed. For example, ISR measurements at Kharkov showed

18 minimal changes until more than 6 hours into the storm, whereafter reductions in NmF2 and plasma

19 temperature enhancements were observed. Measurements at Sondrestrom showed immediate

20 density reduction and opposing changes in ion and electron temperatures.

21 First, Figure 6 shows the ISR observations at Sondrestrom for $N_{e}, T_{e}, T_{i}$, and northward component

22 of ion drift velocity $\left(V_{p n}\right)$ at 100-600 km altitude during August 1-11, 2011. Coinciding with the

23 onset of the geomagnetic storm (see Figure 2), the observations feature a sharp decrease in $N_{e}$ and $T_{e}$ 
1 in the F-region ionosphere at 2000 UT on August 5. These changes appear to correspond to rapid

2 changes in the horizontal transport of plasma, with enhanced southward flow beginning at storm

3 onset on August 5th in the dusk and nighttime sectors, and then enhanced northward flow in the

4 daytime of the 6th. They have associated effects in $T_{i}$ as large values occupy a broad altitude range,

5 extending from $600 \mathrm{~km}$ down into $300 \mathrm{~km} . N_{e}$ does not recover to pre-storm levels for four days.

6 This is likely due to the major thermospheric composition disturbance that reduces plasma densities

7 at high latitudes (Prölss and Roemer, 1987, Immel et al., 2000). Overall, dramatic changes of the

8 ionosphere in response to the geomagnetic storm disturbance are observed in each of the derived

9 ionospheric parameters.

10 Ionospheric effects of the storm observed over the Millstone Hill ISR are shown in Figure 7. The

11 observations feature a sharp increase in $N_{e}$ at 200-600 km altitude for a few hours before 0 UT on

12 August 6, following the commencement of the geomagnetic storm. This effect is mid-latitude storm

13 enhanced density (SED; Foster, 1993), with characteristic high electron densities observed up to 600

$14 \mathrm{~km}$ during a major uplift of the F-layer in the main phase of this storm. Separate GNSS TEC maps

15 (not shown; Rideout and Coster, 2006) confirm a strong SED plume during this period in the

16 American longitude sector. As shown in a number of studies, (e.g. Foster et al., 2014; Foster and

17 Vo, 2002), storm-time enhancements of this type are accompanied by strong westward and

18 northward transport of the F-layer plasma in the subauroral polarization stream (SAPS), as

19 ionosphere and magnetosphere are together entrained in enhanced sunward convective flow of

20 plasma through geospace, energized ultimately by the solar wind and enhanced ring current effects.

21 Although Millstone Hill velocity measurements are vertical only, observations by the $\sim 840 \mathrm{~km}$

22 altitude DMSP F16 satellite (Strom and Iwanaga, 2005) during a pass traversing Millstone Hill's

23 longitude near 2300 UTC show a clear and strong SAPS feature, with $\sim 1500 \mathrm{~m} / \mathrm{s}$ westward/cross- 
1 track velocity just north of the observatory at 55 degrees magnetic invariant latitude. Fast SAPS

2 driven mid-latitude cross-B fluxes are characteristic of storm periods with dynamic equatorward

3 motion of the plasmasphere boundary layer (Carpenter and Lemaire, 2004) as the plasmapause

4 moves inward and the Region 2 ring current footprint changes.

5 Enhanced Millstone Hill local electron density is highly structured and dynamic during the

6 immediate post-storm period, and is accompanied by upward plasma transport at altitudes below

$7250 \mathrm{~km}$ and periods of downward transport at altitudes above $\sim 300 \mathrm{~km}$. This complex behavior in

8 mid-latitude plasma transport and resulting features in electron density are similar to positive storm

9 effects reported by Goncharenko et al. [2007], and most likely are associated with enhanced

10 meridional neutral wind as concluded by $\mathrm{Lu}$ et al. [2008]. Observation of rapid variations in plasma

11 drift and density are characteristic of surges in equatorward meridional wind, related to traveling

12 atmospheric disturbances launched at higher latitudes.

13 Soon after the largest values are observed in $N_{e}$ during the storm's main phase, the F-layer density

14 drops rapidly to very low values. This is likely a transition in Millstone Hill local conditions to a

15 region where enhanced magnetospheric convection leads to an elevated ion-neutral recombination

16 rate and creates a middle-latitude ionospheric recombination "trough" (Lee et al., 2011; Rodger et

17 al, 1992). In effect, as the storm proceeds and the planet rotates, the origin of parcels of plasma

18 over Millstone Hill switches from the daytime middle latitude to evening sub-auroral regions.

19 Plasma densities in these regions are greatly enhanced and reduced, respectively. The greatly

20 reduced electron density effect may also be the first indication of a mid-latitude neutral composition

21 disturbance. Inspection of North American GNSS TEC maps (Figure 4) confirms the formation of a

22 trough at mid-to-high latitudes (40-60 N geodetic latitude) in the early UT hours of Aug 6, 2011

23 along with a general decrease in TEC at lower latitudes. When the SED effect is present at mid- 
1 latitudes, $T_{e}$ shows a sharp decrease. This effect has been observed previously ( $c f$. Goncharenko et

2 al., 2007; Huang et al., 2005), and is caused by the enhancement in electron cooling rates that are

3 proportional to $N_{e}^{2}$ (Roble, 1975). At the same time, $T_{i}$ shows a marked increase, reflecting the fact

4 that the ion population is strongly coupled to the neutral gas through collisions, and the enhanced

5 ion velocities and frictional heating of the thermospheric gas raises the bulk ion temperature in

6 concert with the gas temperature (Burke et al., 2009). Following this period, though, a significant

7 nighttime increase is evident in both $T_{e}$ and $T_{i}$ and is especially prominent from 200 to $600 \mathrm{~km}$

8 altitude as the expanded convection zone moves MLH's position into regions nearer the ionospheric

9 trough.

10 At lower latitudes, the observations by the ISR at Arecibo in Figure 8 show a significant variability

11 in $N_{e}$ in response to the storm. The increasing $N_{e}$ covers a broad altitude range, with enhancements

12 from $600 \mathrm{~km}$ down into $300 \mathrm{~km}$. A deep depletion occurs thereafter, beginning soon after nightfall at

13 the station (2 UT) that is also seen across the ionosphere from top to bottom. The recovery of

14 nighttime plasma densities is rapid and possibly indicative of transport effect, though the observed

15 trends are quite like the MLH radar observations. Also like the MLH radar observations, daytime

16 ionospheric conditions on August 6 show a greatly reduced abundance of electrons at all altitudes.

17 The ion drift at Arecibo exhibited very large fluctuation during the storm period which caused

18 unusual change in the ion composition. Gong et al. [2013] present a detailed analysis of the

19 response of the ionosphere at Arecibo to these storm-time drivers. The extreme variation in vertical

20 velocities (not shown) have concomitant effects in ionospheric densities and heights, which the

21 bottom panel of Figure 8 shows. One can identify 3 main enhancements in topside plasma density.

22 At $500 \mathrm{~km}$, the enhancements occur at approximately 2130, 2315 and 0130 UT. Gong et al. discuss

23 the relation between vertical velocity, $\mathrm{NmF} 2$ and $\mathrm{hmF} 2$ extensively and the role of winds, 
1 composition, and downward proton transport in affecting them.

2 Figure 9 shows the ISR observations of $N_{e}, T_{e}, T_{i}$, and $V_{o}$ from Jicamarca. The observations around 3 0500-1200 UT on August 6 are contaminated due to the presence of equatorial spread F (ESF), so

4 they are not included in the plot. The variations at the storm onset are subtle, but include a small 5 increase in F-region $N_{e}$ following the storm. Following the data gap caused by the occurrence of 6 ESF, increased $T_{e}$ is observed extending from $600 \mathrm{~km}$ to $200 \mathrm{~km}$ altitude. A small increase in $T_{i}$ is 7 also observed. The larger changes are in $N_{e}$ and $V_{o}$, with the latter showing practically no upwelling 8 of the ionospheric plasma during the day of the $6^{\text {th }}$, a condition not observed on any other day 9 during the study period. One might then expect low electron densities on this day, as this fountain 10 effect is the normal means of lifting and enhancing the daytime equatorial ionospheric density.

11 However, the peak F2-layer density (Figure 9a) evidently increases to much greater values than any 12 other day of the period throughout the daytime of the $7^{\text {th }}$. The height and density of the layer 13 observed at JRO is summarized later in this report.

14 Figure 10 shows the ISR observations during this geomagnetic storm from Kharkov, located $\sim 100^{\circ}$ 15 east of Millstone. As opposed to the American sector, this locale is in darkness for most of the storm 16 main phase. Of the evident storm effects, there is a trend toward reduced $N_{e}$ beginning before 0000

17 UT on August 6, compared to pre-storm levels. There is also a significant increase in $T_{e}$ and $T_{i}$ prior 18 to sunrise ( $\sim 200 \mathrm{UT})$, continuing into daytime and a reversal of the usually observed trend of 19 upward ion velocities post midnight (noted on the $4^{\text {th }}, 5^{\text {th }}$ and $7^{\text {th }}$ ), showing downward flows prior to 20 sunrise on the $6^{\text {th }}$. These interrelated changes are possibly the result of several phenomena including 21 1) development of a middle latitude disturbance wind dynamo and 2) reduction of electron and ion 22 cooling rates due to reduction in either the electron densities themselves, or atomic oxygen

23 densities. These processes develop naturally from the storm-time heating occurring at high latitudes, 
1 and subsequent advection of plasma temperature and neutral composition disturbances to middle

2 latitudes by enhanced neutral winds. The resulting effects may be seen in the enhanced Te and Ti

3 after sunrise [Schunk and Nagy, 1978; Chernogor et al., 2007], and in the strong downward ion

4 velocities in the 2300-0200 UT period [Blanc and Richmond, 1980]. Specifically, the Blanc and

5 Richmond model of the disturbance electric field predicts eastward electric fields of $\sim 1-2 \mathrm{mV} / \mathrm{m}$ in

6 this time period, thus imparting a significant downward velocity to the F-layer. Given that the storm

7 is in recovery phase by $0200 \mathrm{UT}$, it is not likely that magnetospheric electric potentials extend to the

8 latitude of KHA, and are unlikely to be the cause of effects observed after 0200 UT.

9 From each of the previously presented ISR data at low and middle latitudes, the storm effects can be 10 summarized by deriving the F-layer height and density parameters, hmF2 and NmF2. These are

11 shown in Figure 11, where the departure from prior trends can be observed at every station. Notably, 12 middle latitude stations all show F-layer height increases, followed by significant F-layer density 13 reductions. JRO (Figure 11d) stands out from this trend, showing a remarkable enhancement in the

14 F-layer density with lower heights (by 20-50 km) during storm recovery on August 6, between $\sim 15$ 15 and $24 \mathrm{UT}$.

16 This could strictly be related to changes in the plasma density profile, with little change in the total 17 plasma content over JRO. To address this, another key parameter of storm effects, the total electron 18 content (TEC), is derived from each of the $\mathrm{N}_{e}$ data shown in the previous figures, and shown in

19 Figure 12. It is clear from this that an enhancement in TEC over JRO is observed in the same period 20 as . An overall $\sim 20-30 \%$ greater abundance of plasma is observed overhead at any time in the day of 21 storm recovery relative to prior days.

22 One possible explanation is that the relative abundance of atomic oxygen neutral gas is enhanced 
1 after the storm. TIMED GUVI can provide some indication of whether this is supported by

2 thermospheric observations. TIMED determines the $O / N_{2}$ ratio globally once per day when orbiting

3 away from the solar terminators. In this case, the local time of the GUVI observations is 07:00 LT,

4 and airglow brightnesses are sufficient for determination of $O / \mathrm{N}_{2}$ from the single track

5 spectrographic mode measurements that the instrument now obtains continuously. Figure 13 shows

6 the $\mathrm{O} / \mathrm{N}_{2}$ on August 6 compared to conditions on the previous day, when activity was very low. The

7 first tracks come from the Asian sector, where the $O / N_{2}$ perturbation is not very large, but it grows

8 in magnitude as the tracks continue to the West. The $O / N_{2}$ is not interpretable over Jicamarca due to

9 the fact of contamination of the GUVI detector by radiation belt particles in the South Atlantic

10 Anomaly. However, the regions around South America show small increases in $O / N_{2}$ with increases

11 of $\sim 20 \%$ in the ratio over Ecuador. It is possible that the region in the vicinity of JRO experienced

12 an increase in $\mathrm{O} / \mathrm{N}_{2}$ on the order of $20 \%$ and a corresponding change in net ionospheric production

13 rates driven by solar EUV. If this is the case, it would account for the corresponding factor of 1.2-

141.3 increase in TEC over Jicamarca after the geomagnetic storm. In fact, the dynamical variations in

15 the Chapman parameters suggest strong downward winds as the expanded and enhanced regions of

16 auroral heating drive a global Hadley-type circulation with resultant downwelling gas and enhanced

$17 \mathrm{O} / \mathrm{N}_{2}$ throughout the vertical column of air in the thermosphere near the equator.

\section{3. Discussion}

19 The August 2011 geomagnetic storm was observed to have major effects on the density and

20 dynamics of the ionospheric plasma from the auroral zone to the equator. A major effect is to modify

21 ionospheric densities globally. Reductions generally occur through either enhanced ion

22 recombination driven by bulk convective motion of the plasma, or by enhancement of the molecular

23 neutral species. The radars themselves can provide a measure of the bulk motion and drift-enhanced 
1 recombination, but the change in the neutral gas that comes with storms is necessarily observed by

2 other means, in this case by TIMED GUVI. The temporal cadence of the TIMED measurements is

324 hours, but the "memory" of the composition effect is also on the order of hours, regulated by the

4 diffusion of the various species throughout the atmospheric column.

5 The most remarkable reduction in plasma density is observed at Arecibo (ARO Figure 8), with

6 similar strong nighttime reduction also seen at SON (Figure 6) and MLH (Figure 7), followed by

7 significant suppression of the growth of electron densities through the following day. This

8 suppression is clearly related to the composition disturbance, and the continued negative storm

9 effects that remain, imprinted on the thermosphere following a $\sim 6 \mathrm{~h}$ period of high latitude heating,

10 and slowly wane to seasonal levels over the 24-36 hours that follow. Different behavior is observed

11 for more longer lasting geomagnetic storms, where equatorward-directed winds from high latitudes

12 provide a more continuous drag on the F-region plasma, lifting the plasma along the magnetic field

13 lines and maintaining enhanced F-layer densities for longer durations. Pincheira et al. (2002) give

14 several examples of the occurrence of this process for historical storm events.

15 An observation that ties much of the observations together are the TIMED GUVI measurements,

16 where it is evident that thermospheric $O / N_{2}$ is significantly enhanced at low and equatorial latitudes.

17 Conversely, it is reduced at middle and high latitudes, predominantly in the Northern Hemisphere

$18(\mathrm{NH})$, this latter point due to the fact that it is Northern Summer and the additional insolation and

19 conductivity in the auroral zone leads to greater high latitude heating in the $\mathrm{NH}$ and greater

20 equatorward inner-hemispheric winds [Fuller-Rowell et al., 1996]. In the convergence of winds

21 originating in the polar regions during a geomagnetic storm in August, the northern hemisphere

22 winds are larger and the band of maximum subsidence is therefore found generally south of the

23 equator. This is borne out in the global GUVI observations and may explain the extreme post-storm 
1 enhancement of JRO densities. Furthermore, the images show a major reduction in thermospheric

$2 \mathrm{O} / \mathrm{N}_{2}$ in the vicinity of ARO and up to MLH and SON. It is clear that the reduction in densities at

3 these stations may be attributed in large part to the composition disturbance, with the additional

4 strong effect of disturbance winds being largest at Arecibo. Unfortunately, the vertical drift

5 measurements at Arecibo were difficult to derive during the World Day period, given the large

6 composition changes observed there [Gong et al., 2013].

7 The generation of a strong disturbance dynamo by this storm is evidenced by the ionospheric

8 measurements at JRO (Figure 9), where the ionospheric peak height is lower than quiet days during

9 the storm recovery on August 6 and upward plasma drifts are near zero much of the day. This is

10 likely due in part to disturbed zonal winds that produce dynamo fields counter to the normally

11 generated $S q$ fields. The surprising observation is the counter intuitive finding that the ionospheric

12 peak is also denser than any other time during the World Day period. The presence of a oxygen-rich

13 composition environment, discussed above, is therefore deemed a likely component of the physical

14 processes that contribute to the stormtime variability at JRO.

16 4. Summary

17 This study presents the coordinated observations of the ionosphere by ISRs at Sondrestrom $\left(67^{\circ} \mathrm{N}\right)$,

18 Millstone Hill $\left(42.6^{\circ} \mathrm{N}\right)$, Arecibo $\left(18.3^{\circ} \mathrm{N}\right)$, and Jicamarca $\left(11.95^{\circ} \mathrm{S}\right)$ along the $\sim 70^{\circ} \mathrm{W}$ meridian, and

19 Kharkov (36.3 $\left.{ }^{\circ} \mathrm{E}\right)$ for August 1-11, 2011 during the URSI World Day campaign. These observations

20 coincide with a major geomagnetic storm occurring on August 5, with $K p$ index increases to 8 and

$21 D s t$ decreases to -100 nT. These campaign observations allow the study of the ionospheric variations

22 in response to the geomagnetic storm at various latitudes. 
1 In summary, we find the following effects:

2 1) Major enhancements in ionospheric density at 400-600 km altitude in the afternoon sector at

3 storm onset at MLH and ARO, indicative of the expansion of magnetospheric convection fields well

4 into middle latitudes.

5 2) The nearly complete elimination of the F-layer at nighttime at SON, MLH, and ARO,

6 accompanied by strong spread-F at JRO, at the peak of the magnetic storm.

7 3) Major reductions ( $\sim 50 \%)$ in ionospheric density at middle and high latitudes during the storm 8 recovery in daytime, as compared to pre-storm values.

9 4) Major enhancement (100\%) in equatorial F-layer peak density at the equator during storm 10 recovery in daytime, as compared to pre-storm values.

11 These data show the remarkable behavior of the coupled inner magnetospheric-ionospheric system, 12 and evidence for strong control of the ionospheric state by the thermospheric composition, which is 13 in turn modified by magnetospheric inputs and joule heating variability, preconditioned by the 14 seasonal trends of solar EUV production of ionospheric conductivities and driven by the strong solar 15 wind drivers. The resultant remarkable enhancement in the equatorial ionosphere shows the 16 importance of global scale studies with both global and regional measurements to capture the 17 behavior in order to understand the physical behavior of geospace. Further studies should invoke 18 numerical modeling efforts to confirm the findings elicited from direct observations. Also, this study 19 points to the need for $O / N_{2}$ measurements in the South American region uncontaminated by the 20 harsh regional environment of the measurement in LEO orbits. This could come from global UV 21 imagers in geosynchronous orbits that are not susceptible to the contamination of in-situ sensors, or 22 from new UV sensors in LEO orbits that either through shielding or operational techniques provide 
$1 \mathrm{O} / \mathrm{N}_{2}$ measurements unaffected by SAA radiation. Two new NASA missions, ICON and GOLD, will

2 though their unique implementations provide the $O / N_{2}$ measurements in these adverse conditions.

3 Without these measurements, a key parameter of the environment that supports the growth of these

4 large plasma densities is basically unknown.

6 Acknowledgements

7 This research work was supported by the National Science Foundation's CEDAR program through

8 Award AGS-1042261, NSF's Aeronomy program through Award AST-1019065 and the National

9 Aeronautics and Space Administration's Heliophysics Research program through Award

10 NNX12AD48G. We thank the URSI incoherent scatter radar working group (ISWG) for helping

11 with the organization of this world day campaign. The Arecibo Observatory is operated by SRI

12 International under a cooperative agreement with NSF (AST-1100968), an in alliance with Ana G.

13 Mendez-Universidad Metropolitana, and the Universities Space Research Association. Work at the

14 MIT Haystack Observatory has been supported by NSF Co-operative Agreement ATM-0733510

15 with the Massachusetts Institute of Technology. The Jicamarca Radio Observatory is a facility of the

16 Intituto Geofisico del Peru operated with support from the NSF AGS-0905448 through Cornell

17 University. The Sondrestrom Radar measurements and analysis are supported under cooperative

18 agreement NSF EAR-0836152 between NSF and SRI International. Work at Miami University was

19 supported by NSF CEDAR grant AGS-1042223. The ACE satellite data are obtained from the ACE

20 Science Center and we acknowledge E. Ness and D. McComas for their provision of these data. The

21 Dst and Kp index data are available at the World Data Center for Geomagnetism. THEMIS data are

22 provided by NASA contract NAS5-02099. Specifically we thank K.H. Glassmeier, U. Auster and W. 
Baumjohann for the use of THEMIS FGM data provided under the lead of the Technical University

of Braunschweig and with financial support through the German Ministry for Economy and

Technology and the German Center for Aviation and Space (DLR) under contract 50 OC 0302.

\section{References}

Angelopoulos, V., et al. (2008), First Results from the THEMIS Mission, Space Sci. Rev., 141, 453476.

Blanc, M., and A. D. Richmond (1980), The ionospheric disturbance dynamo, J. Geophys. Res., 85, 1669-1688.

10 Buonsanto, M. J. (1999). Ionspheric storms - a review. Space Sci. Rev. 88, 563-601.

11 Buonsanto, M. J., S. A. González, X. Pi, J. M. Ruohoniemi, M. P. Sulzer, W. E. Swartz, J. P.

12 Thayper, D.N. Yuan (1999a). Radar chain study of the May, 1995 storm. J. Atmos. and Solar-Terr.

13 Phys, 61, 233-248.

14 Buonsanto, M. J., S. A. González, G. Lu, B. W. Reinisch, J. P. Thayer (1999b), Coordinated

15 incoherent scatter radar study of the January 1997 storm. J. Geophys. Res., 104, 24,625-24,637.

16 Burke, W. J., C. S. Lin, M. P. Hagan, C. Y. Huang, D. R. Weimer, J. O. Wise, L. C. Gentile, and F. A. 17 Marcos (2009), Storm time global thermosphere: A driven-dissipative thermodynamic

18 system, J. Geophys. Res., 114, A06306.

Chernogor, L. F., Ye. I. Grigorenko, V. N. Lysenko, and V. I. Taran (2007), Dynamic processes in the iono- sphere during magnetic storms from the Kharkov incoherent scatter radar observations, Int. J. Geomagn. Aeron., 7, GI3001, doi:10.1029/2005GI000125.

Christensen, A. B., et al. (2003), Initial observations with the Global Ultraviolet Imager (GUVI) in the NASA TIMED satellite mission, J. Geophys. Res., 108, 16-1.

Carpenter, D., and J. Lemaire (2004), The plasmasphere boundary layer, Ann. Geophys., 22, 42914298.

26 Earle, G. D., and M. C. Kelley (1987), Spectral studies of the sources of ionospheric electric fields.

27 J. Geophys. Res., 92, 213-224.

28 Emmert, J. T., B. G. Fejer, G. G. Shepherd and B. H. Solheim (2004), Average nighttime F region

29 disturbance neutral winds measured by UARS WINDII: Initial results, Geophys. Res. Lett., 31,

30 L22807, doi:10.1029/2004GL021611.

31 Fejer, B. G., and L. Scherliess (1997). Empirical models of storm time equatorial zonal electric

32 fields. J. of Geophys. Res., 102, 24,047-24,056.

33 Foster, J. C., Storm time plasma transport at middle and high latitudes (1993), J. Geophys. Res., 98,, 34 1675-1689.

35 Foster, J. C., P. J. Erickson, A. J. Coster, S. Thaller, J. Tao, J. R. Wygant, and J. W. Bonnell (2014),

36 Storm time observations of plasmasphere erosion flux in the mag- netosphere and ionosphere, 
Geophys. Res. Lett., 41, 762-768, doi:10.1002/ 2013GL059124.

Foster, J. C., and H. B. Vo (2002), Average characteristics and activity dependence of the subauroral polarization stream, J. Geophys. Res., 107(A12),1475, doi: 10.1029/2002JA009409.

Fuller-Rowell, T. J., M. V. Codrescu, H. Rishbeth, R. J. Mo $\square$ ett, and S. Quegan (1996), On the seasonal response of the thermosphere and ionosphere to geomagnetic storms, J. Geophys. Res., 101, 2343-2353.

Goncharenko, L. P., J. E. Salah, A. van Eyken, V. Howells, J. P. Thayer, V. I. Taran, B. Shpynev, Q. Zhou, and J. L. Chau (2005). Observations of the April 2002 geomagnetic storm by the global network of incoherent scatter radars. Ann. Geophys., 23, 163-181.

Goncharenko L. P., J. C. Foster, A. J. Coster, C. Huang, N. Aponte, L. J. Paxton (2007), Observations of a positive storm phase on September 10, 2005, J. Atmos. and Solar-Terr. Phys., 69, 12 1253-1272.

Gong, Y., Q. Zhou, S. D. Zhang, N. Aponte, M. Sulzer, and S. Gonzalez (2013), The Fregion and topside ionosphere response to a strong geomagnetic storm at Arecibo, J. Geophys. Res., A118, 5177 -5183, doi:10.1002/jgra.50502.

Gonzales, C. A., M. C. Kelley, B. G. Fejer, J. F. Vickrey, and R. F. Woodman (1979), Equatorial electric fields during magnetically disturbed conditions, II, Implications of simultaneous auroral and equatorial measurements. J. Geophys. Res., 84, 5803-5812.

Huang, C.-S., J. C. Foster, L. P. Goncharenko, P. J. Erickson, W. Rideout, and A. J. Coster (2005), A strong positive phase of ionospheric storms observed by the Millstone Hill incoherent scatter radar and global GPS network, J. Geophys. Res., 110, A06303.

Immel, T. J., J. D. Craven, and A. C. Nicholas (2000), The DE-1 auroral imager's response to the FUV dayglow for thermospheric studies, J. Atmos. Solar-Terr. Phys., 62, 47-64.

Kelley, M. C., J. J. Makela, J. L. Chau, and M. J. Nicolls (2003), Penetration of the solar wind electric field into the magnetosphere/ionosphere system. Geophys. Res. Lett. 30, 4, 1158-1160, doi:10.1029/2002GL016321.

Lee, I. T., W. Wang, J. Y. Liu, C. Y. Chen, and C. H. Lin (2011), The ionospheric midlatitude trough observed by FORMOSAT-3/COSMIC during solar minimum, J. Geophys. Res., 116, 6311. ionospheric positive storm phase driven by neutral winds, J. Geophys, Res., 13, A08304, doi:10.1029/2007JA012895.

Newell, P. T., T. Sotirelis, K. Liou, and F. J. Rich (2008), Pairs of solar wind-magnetosphere coupling functions: Combining a merging term with a viscous term works best, J. Geophys. Res., $113,4218$.

Pincheira, X. T., M. A. Abdu, I. S. Batista, and P. G. Richards (2002), An investigation of ionospheric responses, and disturbance thermospheric winds, during magnetic storms over South American sector, J. Geophys. Res., 107, 1379.

Prölss, G. W., and M. Roemer (1987), Thermospheric storms, Adv. Space Res., 7 , 223-235. 
1 Reddy, C.A., V.V. Somayajulu, and C.V. Devasia (1979), Global scale electrodynamic coupling of

2 the auroral and equatorial dynamo regions. J. Atmos.. Terr. Phys, 41(2), 189-201.

3 Rideout, W. and A. Coster (2006), Automated GPS processing for global total electron content data,

4 GPS Solutions, 10, 219-228.

5 Roble, R.G.(1975), The calculated and observed diurnal variation of the ionosphere over Millstone 6 Hill on 23-24 March 1970, Planetary and Space Science, 23, 1017-1033.

7 Rodger, A. S., R. J. Moffett, and S. Quegan (1992), The role of ion drift in the formation of 8 ionisation troughs in the mid- and high-latitude ionosphere - A review, J. Atmos. Terr. Phys., 54, 1930.

10 Scherliess, L., and B. G. Fejer (1997), Storm time dependence of equatorial disturbance dynamo

11 zonal electric fields, J. Geophys Res., 102, 24,037-24,046.

12 Schunk, R., W., and A. F. Nagy (1978), Electron temperature in the F region of the ionosphere:

13 theory and observation, Rev. Geophys., 16, 355-399.

14 Strom, S. R., and G. Iwanaga (2005), Overview and history of the Defense Meteorological Satellite 15 Program, Crosslink, 6, 11-15.

16 Tsyganenko, N. A. (1989), A Magnetospheric magnetic field model with a warped tail current sheet, 17 Planet. Space Sci., 37, 5-20. 


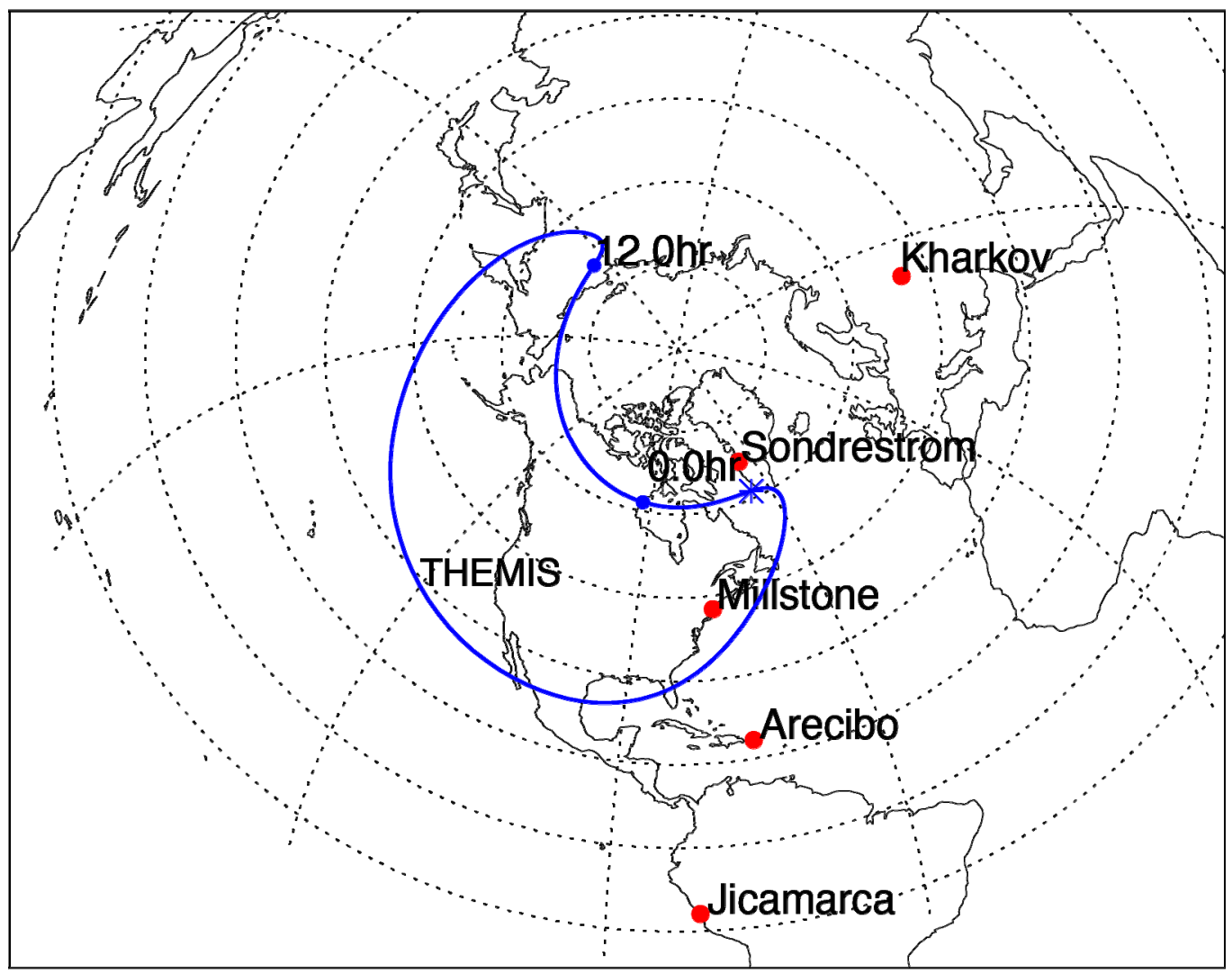

2 Figure 1: Map of the American Sector with ISR locations and THEMIS orbit footpoint noted. The 3 red dots give the locations of the ISRs at Sondrestrom, Millstone Hill, Arecibo, Jicamarca and 4 Kharkov. 

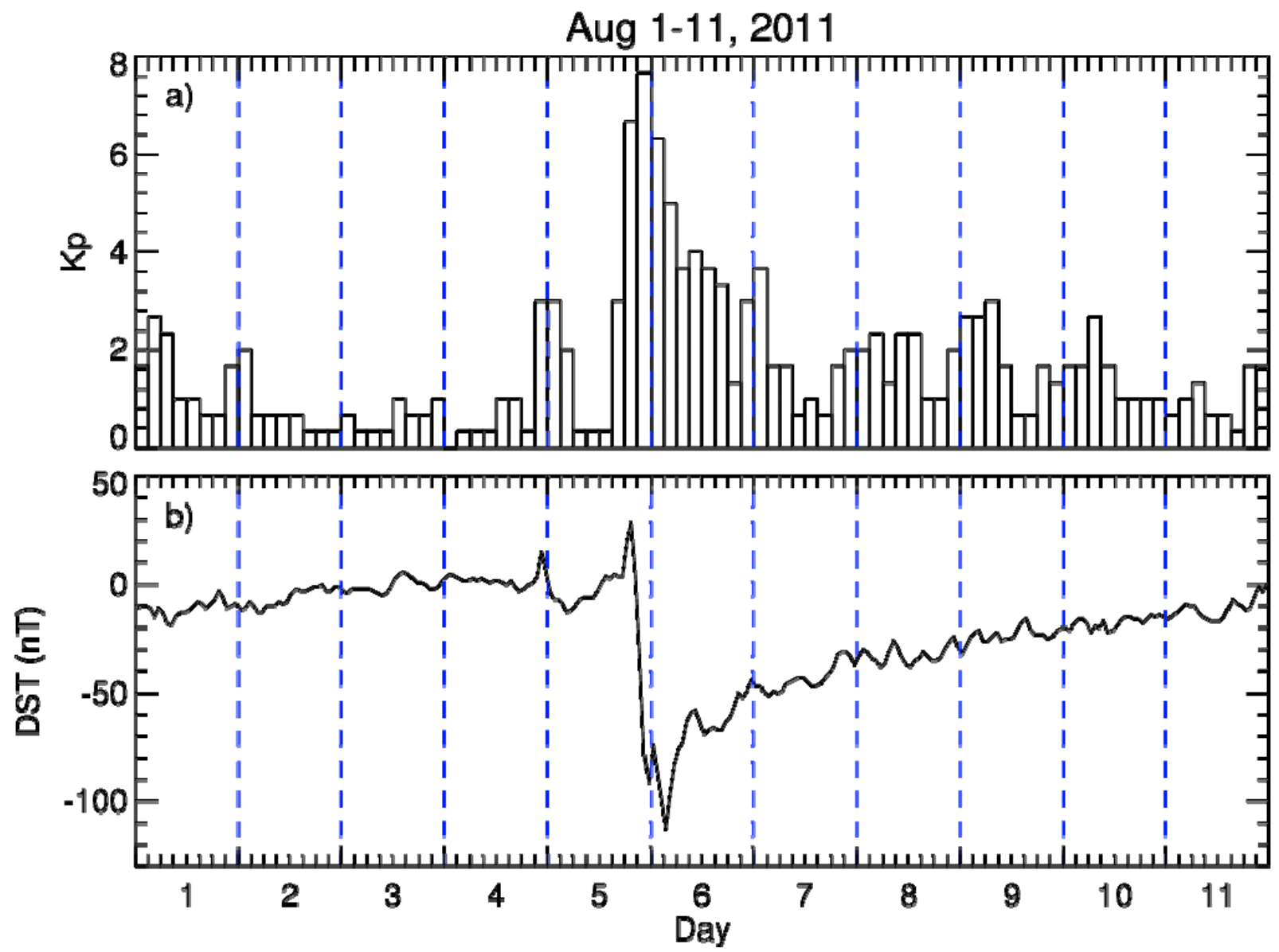

2 Figure 2: Geomagnetic indices of a) 3-hourly $K p$ index and b) Dst index for August 1-11, 2011

3 during the URSI World Day campaign. Note: the day number on the $\mathrm{x}$-axis marks midday. 

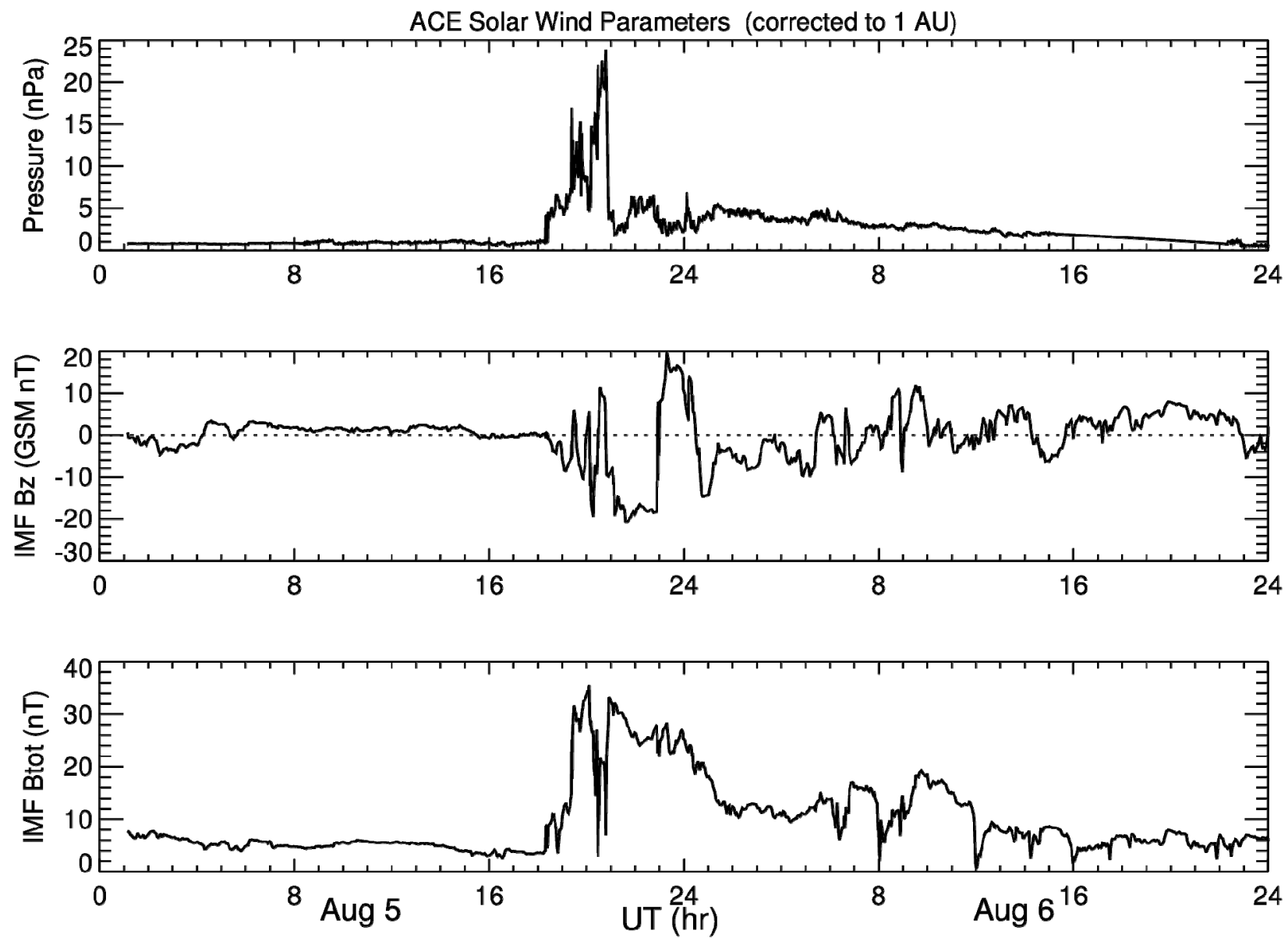

3 Figure 3: Combined solar wind observations of ACE MFI and SWEPAM instruments for August 54 6, 2011 a) solar wind bulk pressure, b) IMF Bz in GSM coordinates and c) IMF $|\mathbf{B}|$. Data are time5 shifted for arrival time at the magnetopause, based upon the 5-minute mean GSM-x velocity at the 6 time of each individual observation. 


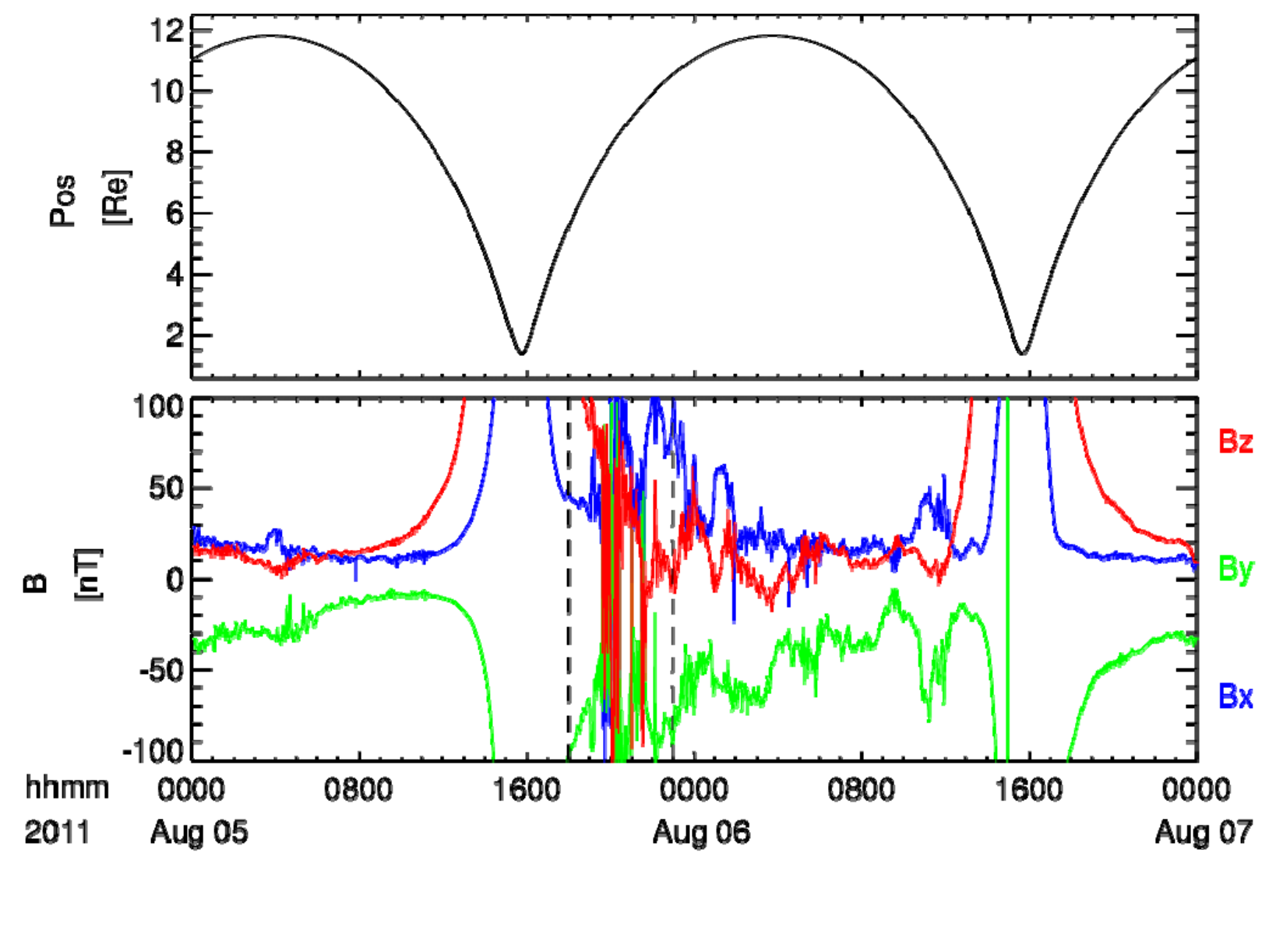

Figure 4: a) Distances of the THEMIS-A satellite to the Earth's center given in units of Earth Radius (Re) for August 5-6, 2011. b) $X, Y$, and $Z$ components of the magnetic field $\boldsymbol{B}$ as observed by THEMIS-A satellite. 

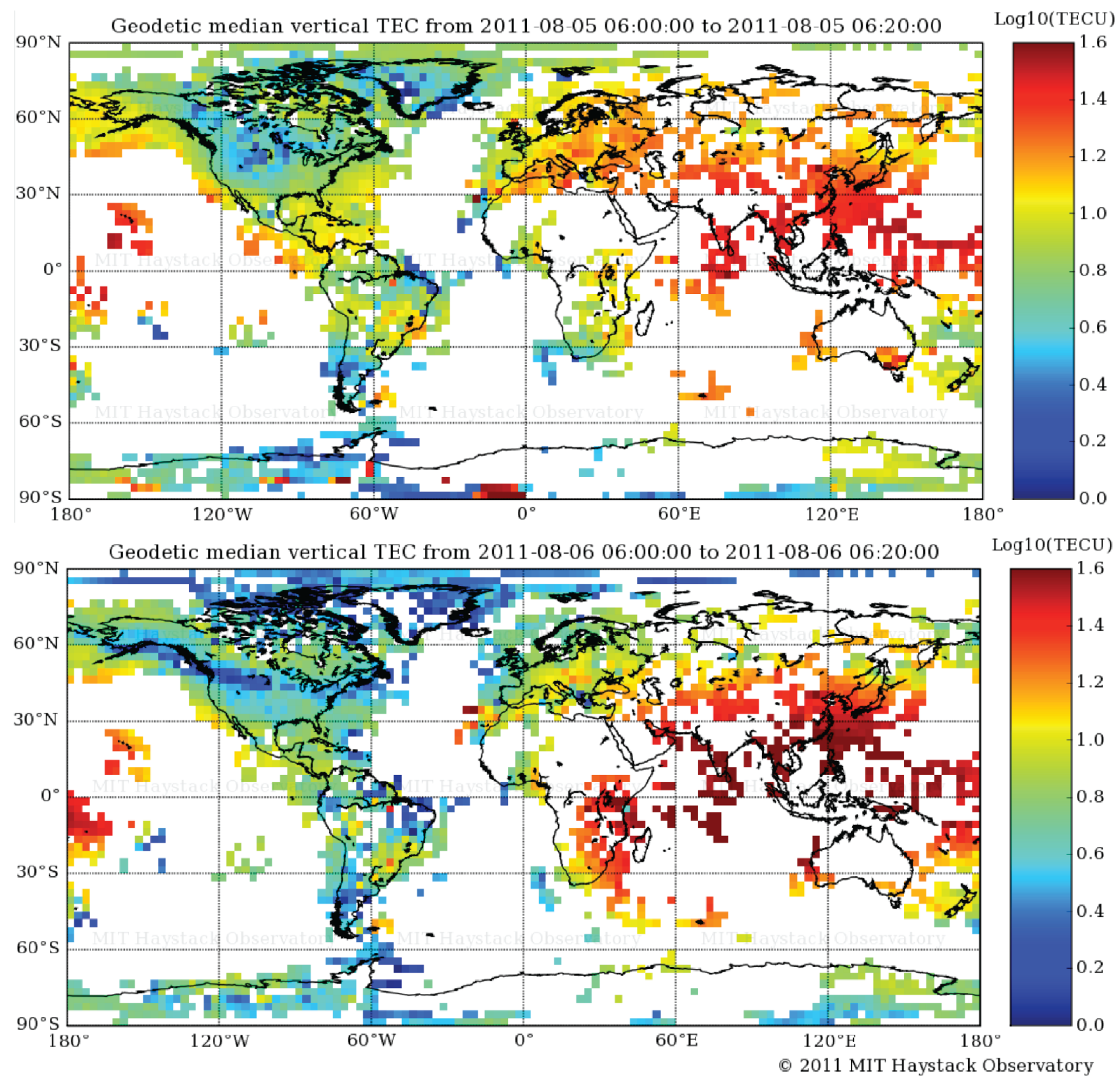

2 Figure 5: Ionospheric vertical total electron content determined from ground based GNNS receivers.

3 Top panel shows pre-storm values, bottom panel shows storm recovery conditions. 


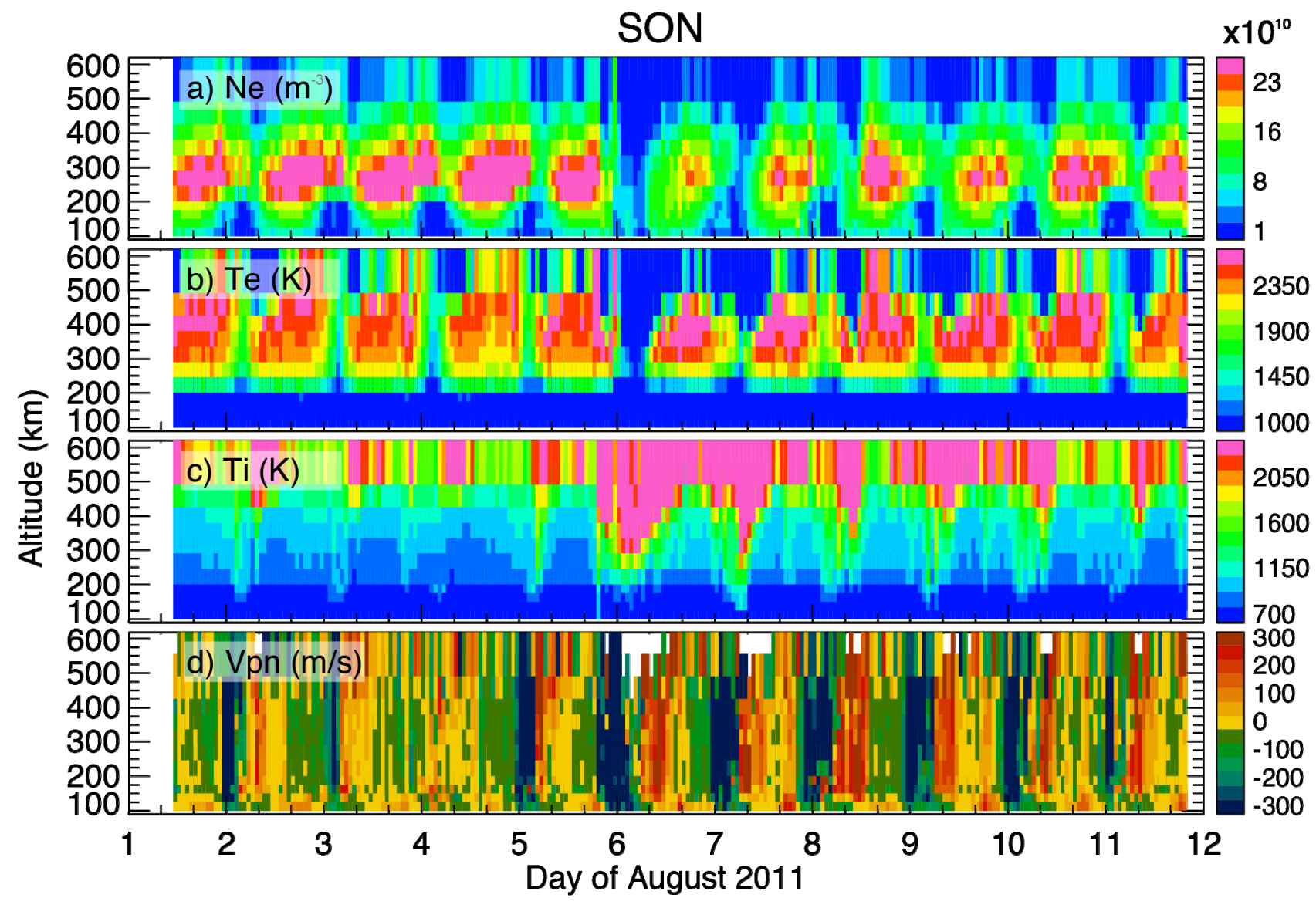

3 Figure 6: The ISR measurements over Sondrestrom $\left(67^{\circ} \mathrm{N}, 51^{\circ} \mathrm{W}\right)$ for a) electron density $\left(N_{e}\right)$, b): 4 electron temperature $\left.\left(T_{e}\right), \mathrm{c}\right)$ ion temperature $\left(T_{i}\right)$, and d) ion velocity perpendicular northward $\left(V_{p n}\right)$ 5 for August 1-11, 2011 during the World Day campaign. 


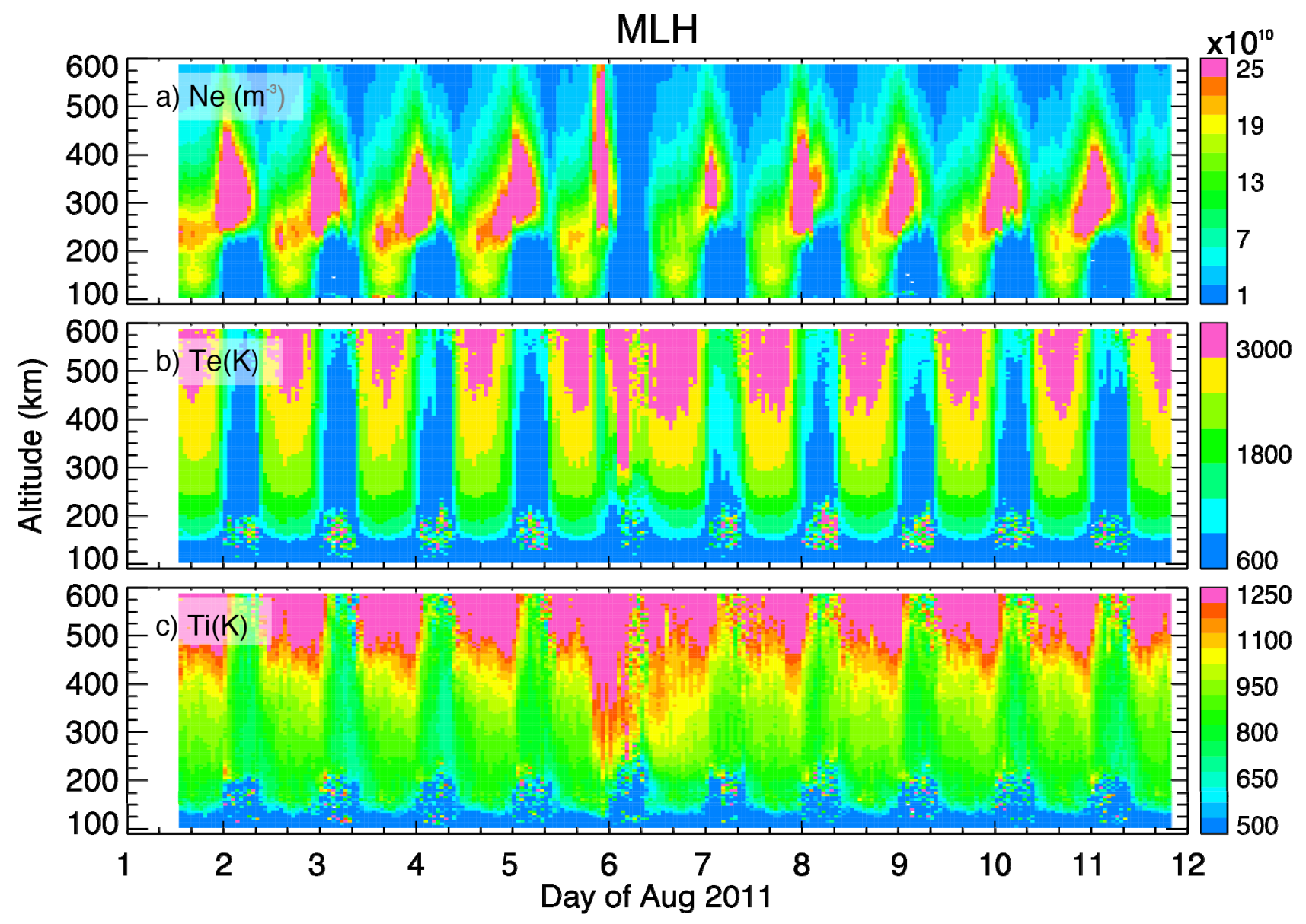

Figure 7: The ISR measurements at Millstone Hill $\left(42.6^{\circ} \mathrm{N}, 71.5^{\circ} \mathrm{W}\right)$ for a): electron density $\left(N_{e}\right)$, b):

3 electron temperature $\left(T_{e}\right)$, and c): ion temperature $\left(T_{i}\right)$ for August 1-11, 2011. 

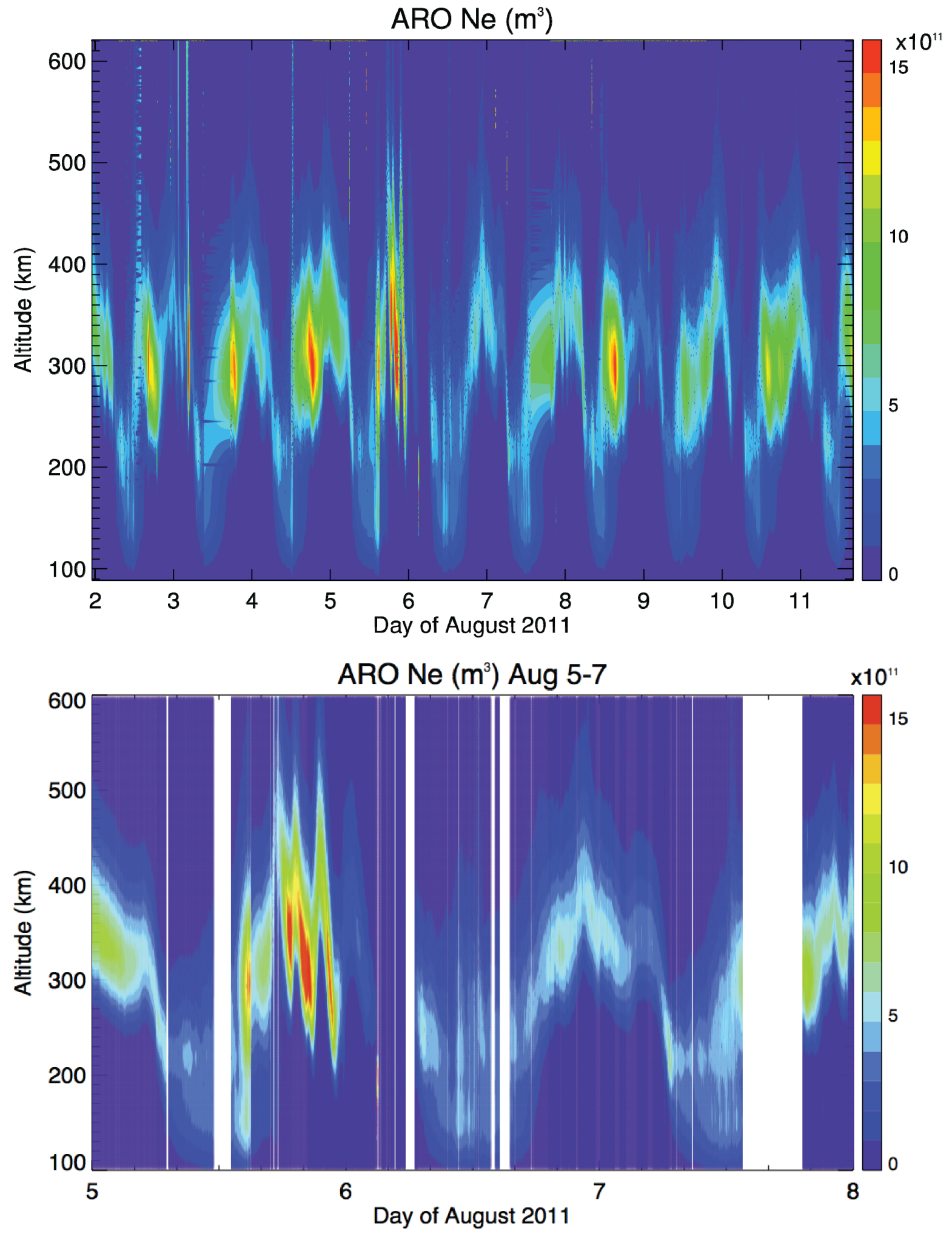
2 Figure 8: The ISR measurements of electron density $\left(N_{e}\right)$ over Arecibo $\left(18.3^{\circ} \mathrm{N}, 66.7^{\circ} \mathrm{W}\right)$ during 3 August 1-11, 2011. The bottom panel provides detail of August 5-7. 


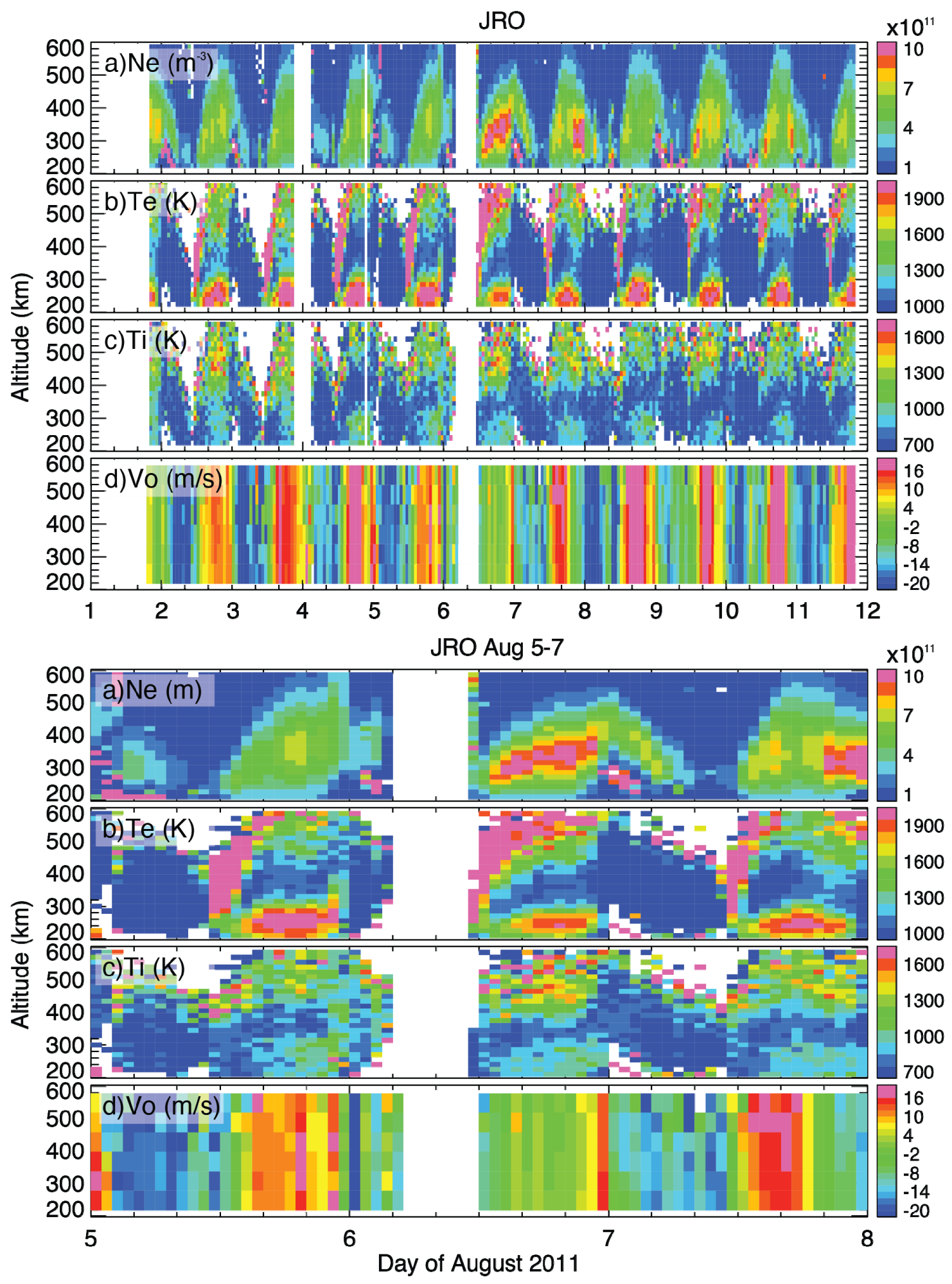

Figure 9: The Jicamarca ISR measurements for a): electron density $\left(N_{e}\right)$, b): electron temperature $\left.\left(T_{e}\right), \mathrm{c}\right)$ : ion temperature $\left(T_{i}\right)$, and $\left.\mathrm{d}\right)$ : vertical ion velocity $\left(V_{o}\right)$ during August 1-11, 2011. Bottom 4 panel is the same set of data, focusing on the three day period including the geomagnetic storm. 


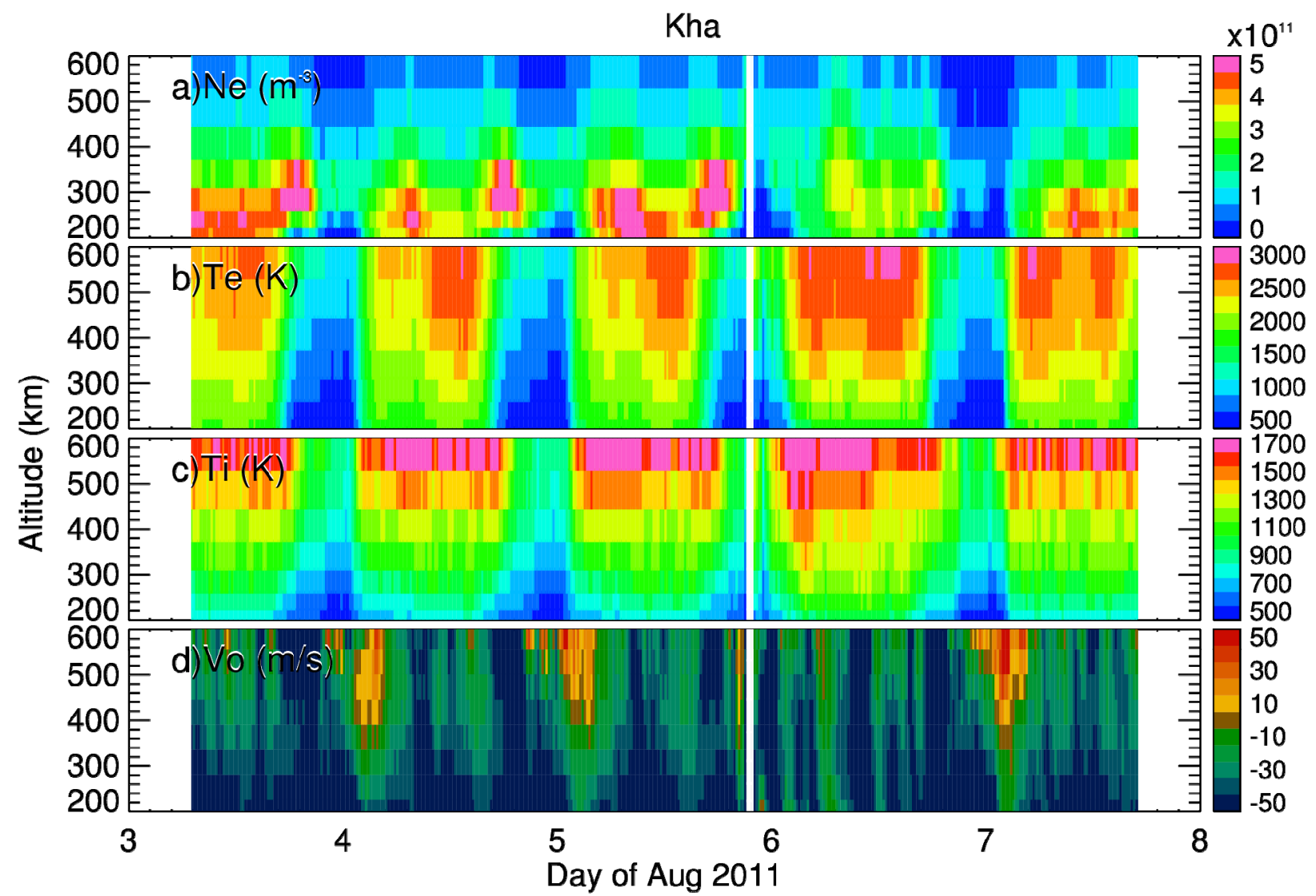

Figure 10: The ISR measurements at Kharkov $\left(49.6^{\circ} \mathrm{N}, 36.3^{\circ} \mathrm{E}\right)$ for a): electron density $\left.\left(N_{e}\right), \mathrm{b}\right)$ : electron temperature $\left.\left(T_{e}\right), \mathrm{c}\right)$ : ion temperature $\left(T_{i}\right)$, and d): vertical ion velocity $\left(V_{o}\right)$ for August 3-7, 2011. 


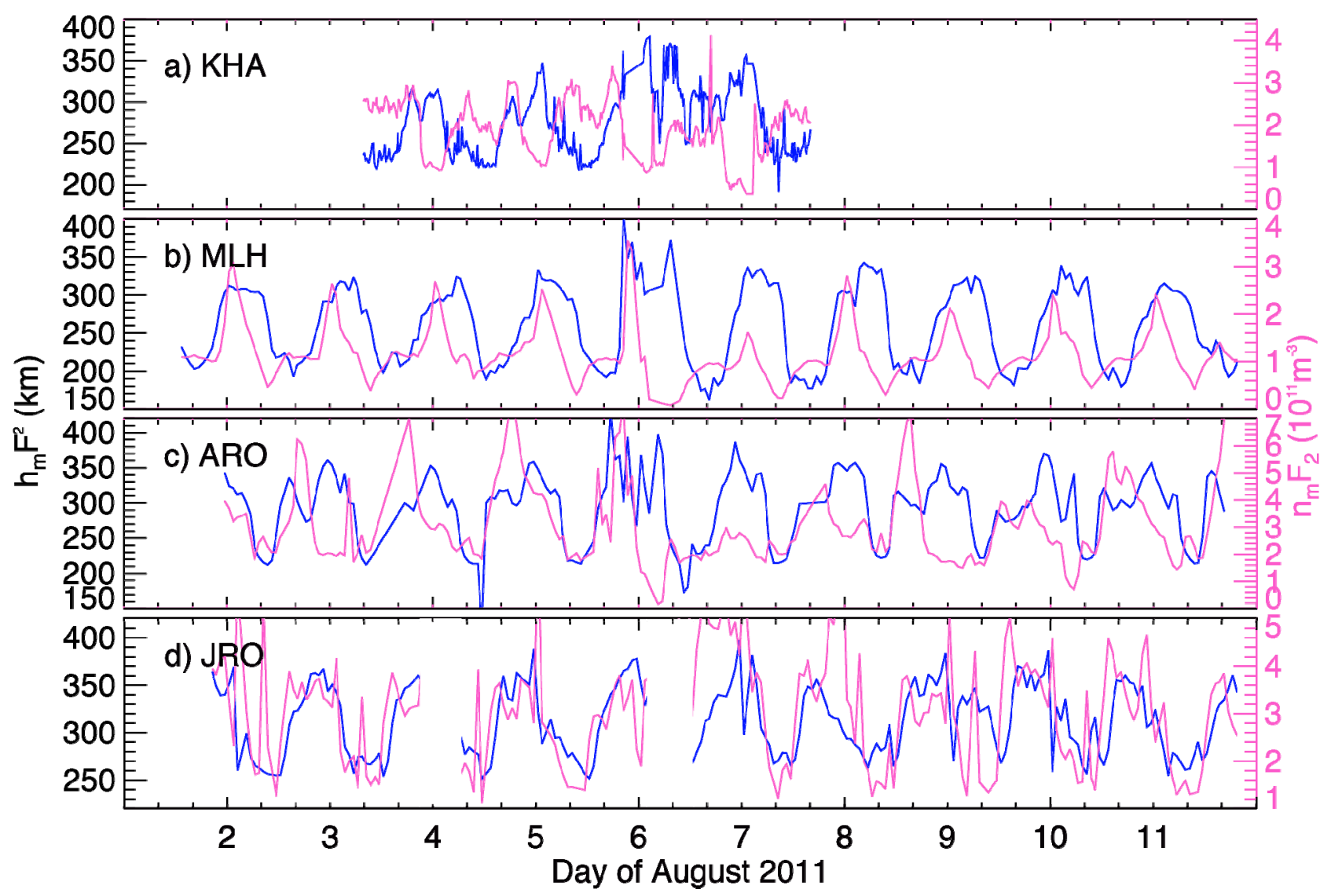

Figure 11. hmF2 (blue) and $\mathrm{NmF} 2$ (red) from the low and middle latitude ISR stations from the World Day period. A two-component Chapman layer is fitted to the $\mathrm{N}_{e}$ values from the 4 stations shown earlier in this report. 


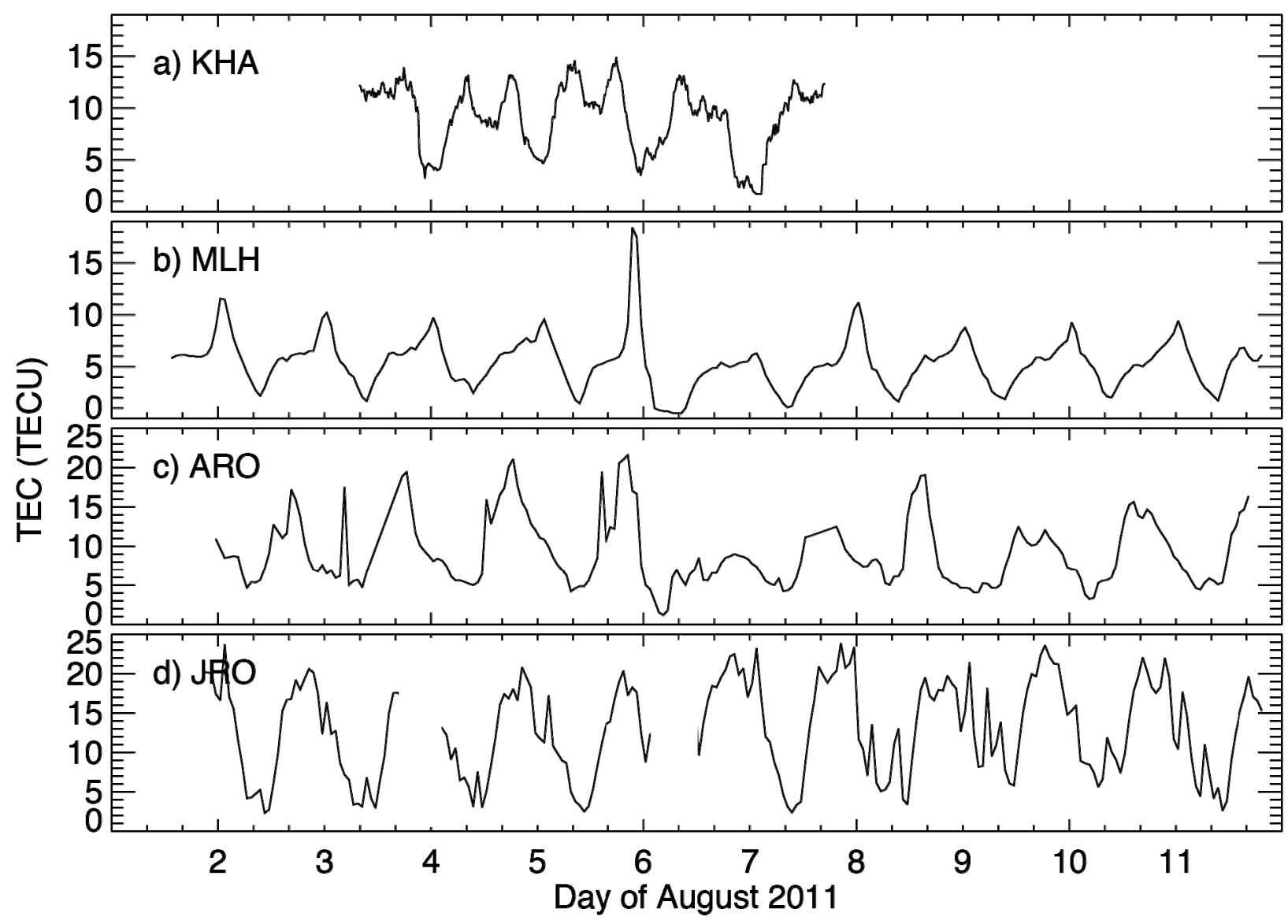

Figure 12. Total electron content (TEC) of the ionospheric layer at the low and middle latitude ISR stations from the World Day period. TEC is determined from the sum of each station's Ne values shown earlier in this report. 


\section{GUVI O/N2}
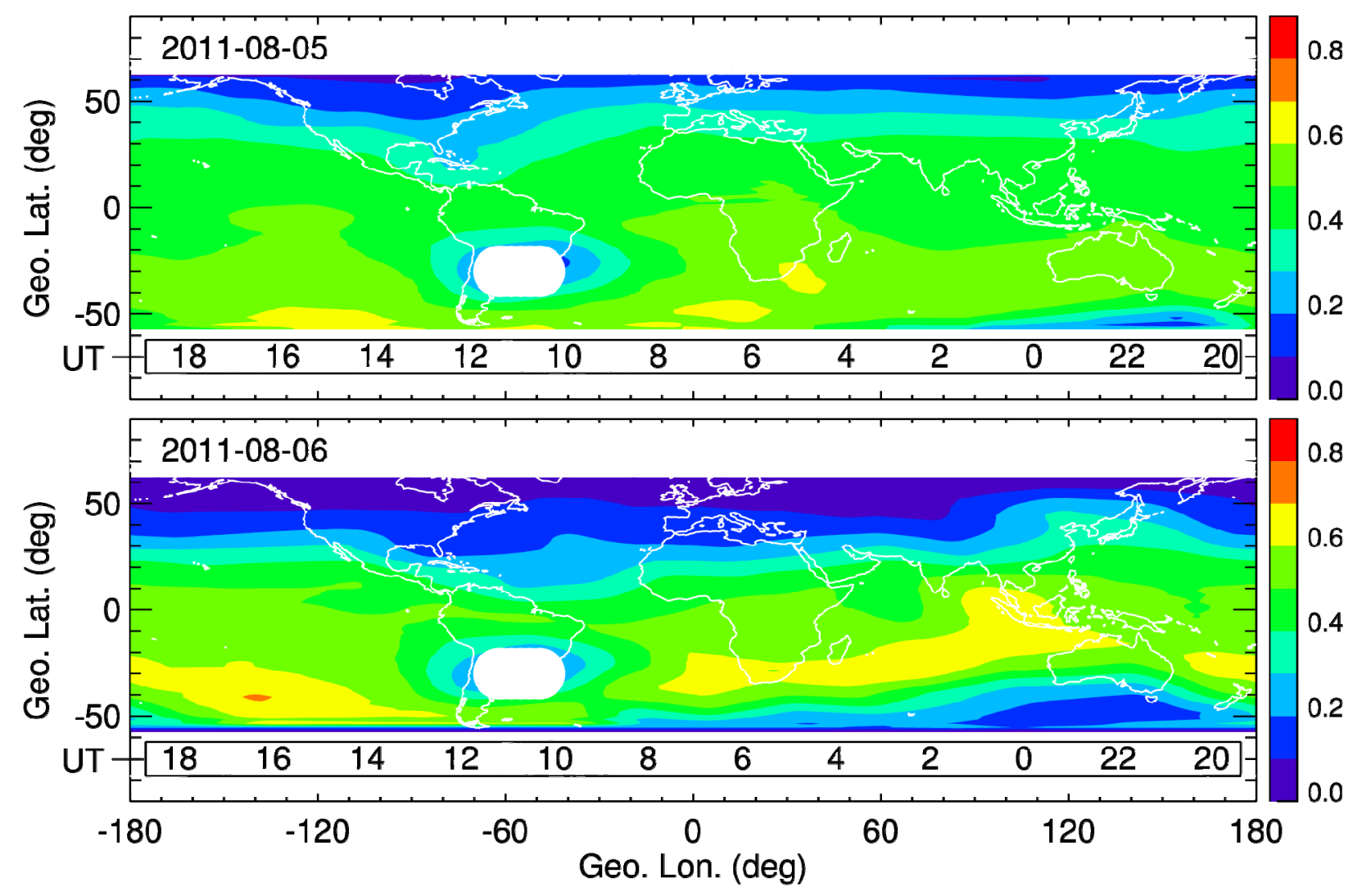

Figure 13: TIMED GUVI thermospheric $O / N_{2}$ determined from 1356/N2 LBH ratios, interpolated from the $\sim 15$ daily tracks obtained in spectrograph mode. Data come from the 0700 LT sector and are collected over 24 hours to produce a global average. 


\begin{tabular}{|c|c|c|c|c|c|c|}
\hline Station & $0-3 h$ & $3-6 \mathrm{~h}$ & $6-12 \mathrm{~h}$ & $12-24 \mathrm{~h}$ & $24-48 h$ & $\begin{array}{l}\text { Altitude/Time } \\
\text { Res shown }\end{array}$ \\
\hline SON & $\downarrow \downarrow \uparrow$ & $\downarrow \downarrow \uparrow$ & 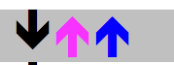 & $\Downarrow \uparrow \uparrow$ & 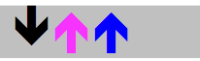 & $25-60 \mathrm{~km} / 1 \mathrm{~h}$ avg \\
\hline MLH & 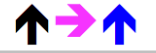 & 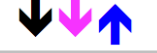 & $\downarrow \uparrow$ & $\downarrow \rightarrow \rightarrow$ & $\rightarrow \rightarrow \rightarrow$ & $5 \mathrm{~km} \quad / 1 \mathrm{~h}$ avg \\
\hline ARO & $\uparrow$ & $\uparrow$ & $\downarrow$ & $\downarrow$ & $\downarrow$ & $.2-4 \mathrm{~km} / 1 \mathrm{~m}$ \\
\hline JRO & $\rightarrow \Rightarrow$ & $\rightarrow \Rightarrow$ & No data & $\uparrow \uparrow$ & $\uparrow \Rightarrow$ & $15 \mathrm{~km} / 1 \mathrm{~h}$ avg \\
\hline KHA & $\Rightarrow \Rightarrow$ & $\Rightarrow \rightarrow \rightarrow$ & ฟハ个 & $\downarrow \rightarrow$ & $\Rightarrow \Rightarrow \rightarrow$ & $/ 15 \mathrm{~m}$ \\
\hline
\end{tabular}

Table 1: Basic changes in F-layer conditions NmF2, $T_{e}$, and $T_{i}$ at each ISR for discrete intervals of geomagnetic storm main phase and recovery. Values of the parameter above or below quiet-time conditions for the local time sector are indicated with vertical arrows. Horizontal arrows indicate conditions similar to undisturbed periods. Also indicated are the key sampling parameters for the data shown in the following figures. 1-h averages are determined from higher resolution measurements. 